\title{
Gene expression profiling of fibroblasts in a family with $L M N A$-related cardiomyopathy reveals molecular pathways implicated in disease pathogenesis
}

\author{
Halida P. Widyastuti ${ }^{1+}$, Trina M. Norden-Krichmar ${ }^{2^{*+}}$, Anna Grosberg ${ }^{3}$ and Michael V. Zaragoza ${ }^{1 *}$ (D)
}

\begin{abstract}
Background: Intermediate filament proteins that construct the nuclear lamina of a cell include the Lamin A/C proteins encoded by the LMNA gene, and are implicated in fundamental processes such as nuclear structure, gene expression, and signal transduction. LMNA mutations predominantly affect mesoderm-derived cell lineages in diseases collectively termed as laminopathies that include dilated cardiomyopathy with conduction defects, different forms of muscular dystrophies, and premature aging syndromes as Hutchinson-Gilford Progeria Syndrome. At present, our understanding of the molecular mechanisms regulating tissue-specific manifestations of laminopathies are still limited.

Methods: To gain deeper insight into the molecular mechanism of a novel LMNA splice-site mutation (c.357-2A > $\mathrm{G}$ ) in an affected family with cardiac disease, we conducted deep RNA sequencing and pathway analysis for nine fibroblast samples obtained from three patients with cardiomyopathy, three unaffected family members, and three unrelated, unaffected individuals. We validated our findings by quantitative PCR and protein studies.

Results: We identified eight significantly differentially expressed genes between the mutant and non-mutant fibroblasts, that included downregulated insulin growth factor binding factor protein 5 (IGFBP5) in patient samples. Pathway analysis showed involvement of the ERK/MAPK signaling pathway consistent with previous studies. We found no significant differences in gene expression for Lamin A/C and B-type lamins between the groups. In mutant fibroblasts, RNA-seq confirmed that only the LMNA wild type allele predominately was expressed, and Western Blot showed normal Lamin A/C protein levels.

(Continued on next page)
\end{abstract}

* Correspondence: tnordenk@uci.edu; mzaragoz@uci.edu

${ }^{\dagger}$ Halida P. Widyastuti and Trina M. Norden-Krichmar contributed equally to this work.

2Department of Epidemiology, University of California, Irvine, School of Medicine, 3062 Anteater Instruction and Research Building, Irvine, CA 92697-7550, USA

${ }^{1} \mathrm{UCl}$ Cardiogenomics Program, Department of Pediatrics, Division of Genetics \& Genomics and Department of Biological Chemistry, University of California, Irvine, School of Medicine, 2042 Hewitt Hall, Irvine, CA 92697-3940, USA

Full list of author information is available at the end of the article

(c) The Author(s). 2020 Open Access This article is licensed under a Creative Commons Attribution 4.0 International License, which permits use, sharing, adaptation, distribution and reproduction in any medium or format, as long as you give appropriate credit to the original author(s) and the source, provide a link to the Creative Commons licence, and indicate if changes were made. The images or other third party material in this article are included in the article's Creative Commons licence, unless indicated otherwise in a credit line to the material. If material is not included in the article's Creative Commons licence and your intended use is not permitted by statutory regulation or exceeds the permitted use, you will need to obtain permission directly from the copyright holder. To view a copy of this licence, visit http://creativecommons.org/licenses/by/4.0/ The Creative Commons Public Domain Dedication waiver (http://creativecommons.org/publicdomain/zero/1.0/) applies to the data made available in this article, unless otherwise stated in a credit line to the data. 


\begin{abstract}
(Continued from previous page)
Conclusions: IGFBP5 may contribute in maintaining signaling pathway homeostasis, which may lead to the absence of notable molecular and structural abnormalities in unaffected tissues such as fibroblasts. Compensatory mechanisms from other nuclear membrane proteins were not found. Our results also demonstrate that only one copy of the wild type allele is sufficient for normal levels of Lamin A/C protein to maintain physiological function in an unaffected cell type. This suggests that affected cell types such as cardiac tissues may be more sensitive to haploinsufficiency of Lamin A/C. These results provide insight into the molecular mechanism of disease with a possible explanation for the tissue specificity of LMNA-related dilated cardiomyopathy.
\end{abstract}

Keywords: LMNA gene, Lamin, Laminopathies, Cardiomyopathy, RNA sequencing, IGFBP5 gene, Fibroblasts, Gene expression, Signaling pathway

\section{Background}

The Lamin A/C (LMNA) gene encodes for Lamin A and Lamin $C$ proteins that, along with Lamin $B 1$ and Lamin $\mathrm{B} 2$, form an intricate intermediate filament protein meshwork termed the nuclear lamina (NL) and play important roles in maintaining nuclear structure and stability and in fundamental nuclear functions [1-3]. Lamins $\mathrm{A}$ and $\mathrm{C}$ proteins are products of alternative splicing of the LMNA gene. Lamin A is produced from all twelve exons of the gene, while Lamin $C$ is the product of only ten exons. In vivo, Lamin A is produced as prelamin A and undergoes extensive post-translational processing of the $\mathrm{C}$-terminus to become mature Lamin A protein while Lamin $C$ is produced as mature protein [4]. Aside from conveying structural integrity to the nucleus [5], nuclear lamina proteins associate with heterochromatin [6], modulate gene expression by sequestering transcription factors to the nuclear periphery [7], regulate cell cycle progression [8], and regulate molecular signaling such as ERK/MAPK and Wnt Beta-Catenin pathways [9-11]. The diverse roles of the nuclear lamina proteins underscore their importance in maintaining proper cellular function in an organism.

Despite having common functional roles, the expression patterns of Lamin A/C, Lamin B1, and Lamin B2 are different [12]. Lamin $\mathrm{A} / \mathrm{C}$ expression is absent in human and mouse embryonic stem cells but increases once these cells are induced to differentiate [13]. In contrast, Lamin B1 and Lamin B2 expression are ubiquitous throughout development. Lamin B1 is highly expressed in the embryo and its expression persists throughout development [14]. Similarly, Lamin B2 is expressed early during development, and its expression remains ubiquitous during development [15]. Additionally, Lamin A/C expression levels vary among differentiated cell types. They are more highly expressed in multinucleated cells, such as cardiomyocytes, compared to mononucleated cells, such as fibroblasts $[12,16,17]$.

Although Lamin $\mathrm{A} / \mathrm{C}$ is expressed in most differentiated cell types, LMNA mutations predominantly affect mesoderm-derived cell lineages in diseases collectively termed as laminopathies. Laminopathies range from dilated cardiomyopathy (DCM) with conduction defects [18-20] and different forms of muscular dystrophies, such as Emery-Dreyfus Muscular Dystrophy (EDMD) [21-23] and Limb Girdle Muscular Dystrophy type 1B (LGMD1B) [24], to severe disease characterized by premature aging such as Hutchinson-Gilford Progeria Syndrome [25, 26]. LMNA-related DCM with conduction defects is one of the most common forms of inherited dilated cardiomyopathy, second only to DCM associated with mutations in sarcomere protein genes [27, 28], with an estimated 5 to $10 \%$ of cases associated with a heterozygous LMNA mutation [29-31]. Current hypotheses for how LMNA mutations give rise to diseases limited to cardiac tissues include the mechanical defect and the gene expression hypotheses [32]. The mechanical defect hypothesis proposes that LMNA mutation compromises the structural integrity of a cell, subsequently causing the cells to be more prone to necrosis leading to diseases [33]. The gene expression hypothesis proposes that LMNA mutation impairs the NL structure which leads to aberrant epigenetic modification, abnormalities in signaling transduction and ultimately affecting proper gene expression [32, 34]. As of now, it remains unclear which of these mechanisms is the main cause of $L M N A$-related cardiomyopathy.

We recently identified a novel splice-site mutation in the Lamin A/C gene, LMNA c.357-2A > G (p.N120Lfs*5), in a multigenerational family with DCM, heart failure, and sudden death [35]. In this study, we performed RNA sequencing (RNA-seq) to test the hypothesis that the splice-site mutation in the LMNA gene is associated with altered expression of genes that played a significant role in the nuclear lamina structure and function. By deep RNA-seq of patient and control fibroblasts, we evaluated expression of Lamins A and C, tested for aberrant splicing of $L M N A$ transcripts, and altered ratio of $L M N A$ transcript variants. We also sought to determine any compensatory mechanism by Lamin B1 and/or Lamin B2 in response to the mutation.

We further expanded the analyses to examine the most significantly differentially expressed genes across 
the genome, and determine potential pathways affected by the LMNA mutation or other genes and pathways influencing the observed phenotype. Surprisingly, from the RNA-seq data we did not find any significant differential expression for the Lamin isoforms between the sample groups. However, we found plausible genes and pathways that may contribute to the cardiomyopathy phenotype that we observe in this family. Our study highlighted tissue specificity as a major feature of the novel heterozygous LMNA splice-site mutation as evidenced by the lack of changes in nuclear lamina gene expression and absence of aberrant splicing events in patient fibroblasts. The study conducted here laid the foundation for future disease modeling studies in cardiomyocytes to elucidate on the molecular mechanism of the novel $L M N A$ splice-site mutation.

\section{Methods}

\section{Fibroblast collection}

Nine primary fibroblast cell lines were cultured from skin biopsies (Table 1) as previously described [35]. These included cells from six family members: three affected individuals (Patient 1-3) heterozygous for the LMNA splice-site mutation and three unaffected individuals (Control 1-3) who do not have the LMNA splicesite mutation. To serve as Unrelated Controls (U), fibroblast cells from three healthy individuals were obtained from biorepositories (U1: Lonza CC-2511; lot\#: 0000352805; U2: Lonza CC-2511; lot\#: 0000293971; U3: Coriell Institute ND31845). To confirm the LMNA genotype, genomic DNA (gDNA) was extracted from Patient, Control, and Unrelated Control fibroblasts and evaluated by Sanger sequencing of the 12 LMNA exons as previously described [35]. The LMNA genotype for

Table 1 Fibroblast cell samples that were RNA sequenced ( $N=$ 9)

\begin{tabular}{lccc}
\hline Identification & $\begin{array}{c}\text { Lamin A/C } \\
\text { Genotype* }\end{array}$ & $\begin{array}{l}\text { Age (years) at } \\
\text { Cardiomyopathy } \\
\text { Diagnosis }\end{array}$ & $\begin{array}{l}\text { Age (years) } \\
\text { at Skin } \\
\text { Biopsy }\end{array}$ \\
\hline Patient 1 (P1) & $+/-$ & 36 & 38 \\
Patient 2 (P2) & $+/-$ & 58 & 62 \\
Patient 3 (P3) & $+/-$ & 61 & 70 \\
Control 1 (C1) & $+/+$ & - & 49 \\
Control 2 (C2) & $+/+$ & - & 69 \\
Control 3 (C3) & $+/+$ & - & 68 \\
Unrelated Control 1 (U1) & $+/+$ & - & 40 \\
Unrelated Control 2 (U2) & $+/+$ & - & 51 \\
Unrelated Control 3 (U3) & $+/+$ & - & 73 \\
\hline
\end{tabular}

*+/+ homozygous normal allele; +/- heterozygous LMNA splice-site mutation each sample was also confirmed by examining the RNAseq data.

\section{RNA-seq}

Total RNA from Patient, Control, and Unrelated Control fibroblasts (at passage 7) was isolated and quantified as described [35]. RNA-seq studies were conducted on total RNA (3 to $7 \mu \mathrm{g}$ ) at DNA Link USA, Inc. (San Diego, CA) using poly-A RNA enrichment and library preparation. RNA libraries were sequenced as $75 \mathrm{bp}$ paired-end runs with at least 100 million reads per sample on an Illumina NextSeq 500 platform (Additional File 1: Table S1). The raw RNA-seq data (fastq) was stored and transferred using the BaseSpace Sequence Hub (Illumina, San Diego, CA).

\section{Bioinformatics analysis}

Quality control, alignment, and differential expression (DE) RNA-seq data was first examined for quality using FastQC software [36]. Reads were filtered out due to low quality. Low quality bases at the 3 ' and/or $5^{\prime}$ ends of the reads were trimmed. The reads that pass the quality filtering were aligned to the human reference genome (GRCh37/hg19) with TopHat2 alignment software [37]. The average overall read mapping rate was $90.1 \%$ and average concordant pair alignment rate was $85.5 \%$ (Additional File 1: Table S1). DE analysis was performed with the Cufflinks software [38, 39], using upper quartile normalization between the data files. Normalized DE genes between the groups were filtered for absolute fold change $\geq 1.5$, Fragments Per Kilobase of transcript per Million mapped reads (FPKM) $\geq 1$, and that were significant at false discovery rate (FDR)-adjusted $p$-value $\leq 0.05$. $\mathrm{DE}$ of isoforms was provided by cufflinks/cuffdiff2 software to distinguish between the expression of Lamin isoforms. From this list of significantly DE genes, we further filtered the list to include only $\mathrm{DE}$ genes that were expressed similarly between the Unrelated and $\mathrm{Pa}$ tient groups and between the Control and Patient groups. Our rationale to filter the genes using these parameters was to find genes that potentially were affected by the $L M N A$ splice-site mutation. We reasoned that $\mathrm{DE}$ genes that were shared between Control and Unrelated groups were due to intrinsic gene expression differences and not due to the mutation. By looking only at genes that were at the intersection of Unrelated vs. Patient and Control vs. Patient groups, we narrowed down the candidate genes to those that potentially were affected by the mutation.

\section{Visualization and pathway analysis}

Heatmaps of the gene expression in FPKM values of the most highly DE genes were constructed with cummeRbund [40]. Heatmaps were clustered by rows, where each 
row contained the gene expression of a particular gene. Lamin isoforms were visualized in heatmaps along with any other genes of interest. To detect allelic expression of Lamin A/C transcripts, we used the Integrative Genomics Viewer (IGV) software [41] to visualize the distribution of alleles in mapped reads at rs538089 in Exon 5 and rs4641 in Exon 10 for samples found to be heterozygous by Sanger sequencing of gDNA [35]. Finally, Ingenuity Pathway Analysis (IPA) software (Qiagen, Hilden, Germany) was used to determine the top canonical pathways and visualize the significant networks.

\section{qPCR validation of RNA-seq results}

Quantitative PCR (qPCR) assays were performed to validate RNA-seq results for Lamin A, Lamin C, Lamin B1, Lamin B2, and IGFBP5. cDNA was synthesized using QuantiTect Reverse Transcription Kit (Qiagen) from Unrelated, Control and Patient RNA samples. $100 \mathrm{ng} / \mu \mathrm{l}$ cDNA was used as the reaction template with $10 \mu \mathrm{M}$ of pre-designed Kicqstart forward and reverse primer pairs (Sigma Aldrich, St. Louis, MO) specific to Lamin A and Lamin $\mathrm{C}, 10 \mu \mathrm{M}$ of independently designed primer pairs for Lamin B1, Lamin B2, and IGFBP5 (Integrated DNA Technologies, San Diego, CA), and SYBR green dye along with the necessary reaction components (KAPA Biosystems, Wilmington, MA). The reaction was run in three technical replicates for each sample. Comparative $\mathrm{Ct}(\Delta \mathrm{Ct})$ method was used to determine relative quantitative gene expression (QGE) [42, 43]. Beta Actin $(A C T B)$ was used as the housekeeping gene. Statistical analysis was performed using One-Way ANOVA followed by Tukey post hoc test to determine statistical significance between groups. $P$ values less than 0.05 were considered statistically significant. Primer sequences used for validation are provided in Additional File 1: Table S2.

\section{Lamin $\mathrm{A} / \mathrm{C}$ protein level validation}

Patient, Control and Unrelated Control fibroblasts were grown to confluency, harvested using TrypLE Select $1 \mathrm{X}$ (Thermo Fisher Scientific, Waltham, MA), and lysed using cold RIPA buffer supplemented with protease inhibitors cocktail (Sigma-Aldrich, Saint Louis, MO). Protein concentration was quantified using Pierce ${ }^{\mathrm{Tu}}$ BCA Protein Assay Kit (Thermo Fisher Scientific). $50 \mu \mathrm{g}$ of total protein lysate along with protein ladder were run on a Bolt ${ }^{\mathrm{Tm}} 4-12 \%$ Bis-Tris Plus Gels (Thermo Fisher Scientific) under denaturing conditions followed by wet transfer. Target protein was detected using a primary antibody for Lamin A/C (sc-376248, Santa Cruz Biotechnology, Dallas, TX), at $4{ }^{\circ} \mathrm{C}$ overnight followed by incubation with secondary antibody conjugated to HRP (1: 5000, Abcam, Cambridge, UK) for one hour at room temperature. Beta Actin was used as loading control.
Protein visualization was conducted using iBright FL1000 Imaging System and relative quantification of protein bands was performed using ImageJ [44].

\section{Results \\ Expression variability in samples within and between groups}

In this study, we used whole transcriptome DE analysis to investigate the genes and pathways related to LMNArelated cardiomyopathy. Differences between the gene expression in the pooled sample groups (Unrelated, Control, Patient) were observed by plotting the top DE genes (Fig. 1, left panel). By plotting gene expression by replicate, we observed variation within each sample group (Fig. 1, right panel) and found that Patient and Control groups were more similar to each other, compared to samples in the Unrelated Control group. The heatmaps show the heterogeneity between the samples, where the overall trend was that gene expression pattern of the Patient group was more similar to that of the Control group.

\section{Unaltered NL-associated gene and protein expression in patient fibroblasts}

Because we hypothesized that the expression of the $L M N A$ isoforms may be influenced by the LMNA mutation in the patient samples, we examined the expression of the LMNA isoforms individually (Fig. 2). As seen in the heatmap and RNA-seq data (Fig. 2a, Additional File 1: Table S3), although the patients have the LMNA mutation we did not see significant DE between the sample groups for the $L M N A$ isoforms. Next, we investigated whether the predicted exon skipping and aberrant splicing occurred in patient samples by examining the aligned sequences across the $L M N A$ transcript. Here, we observed sequence alignment that corresponds to the presence of exon 2 of $L M N A$ transcript and similar read coverage across all of the LMNA exons for each patient sample (Additional File 2: Figure S1). Therefore, our data is consistent with the lack of exon skipping and aberrant splicing in mutant fibroblasts. We confirmed the RNA-seq data for the nuclear lamina associated genes using $\mathrm{qPCR}$ and found no statistically significant differences in Lamin A and Lamin C (Fig. 2b) as well as Lamin B1 and Lamin B2 expression between all sample groups (Additional File 2: Figure S2). Validation by Western Blot showed that the amount of Lamin A/C proteins did not vary significantly between the Patient and the two control groups (Fig. 2c). In mutant fibroblasts, we also used RNA-seq to confirm that LMNA expression was predominately from the wild type allele [35] (Fig. 3). 

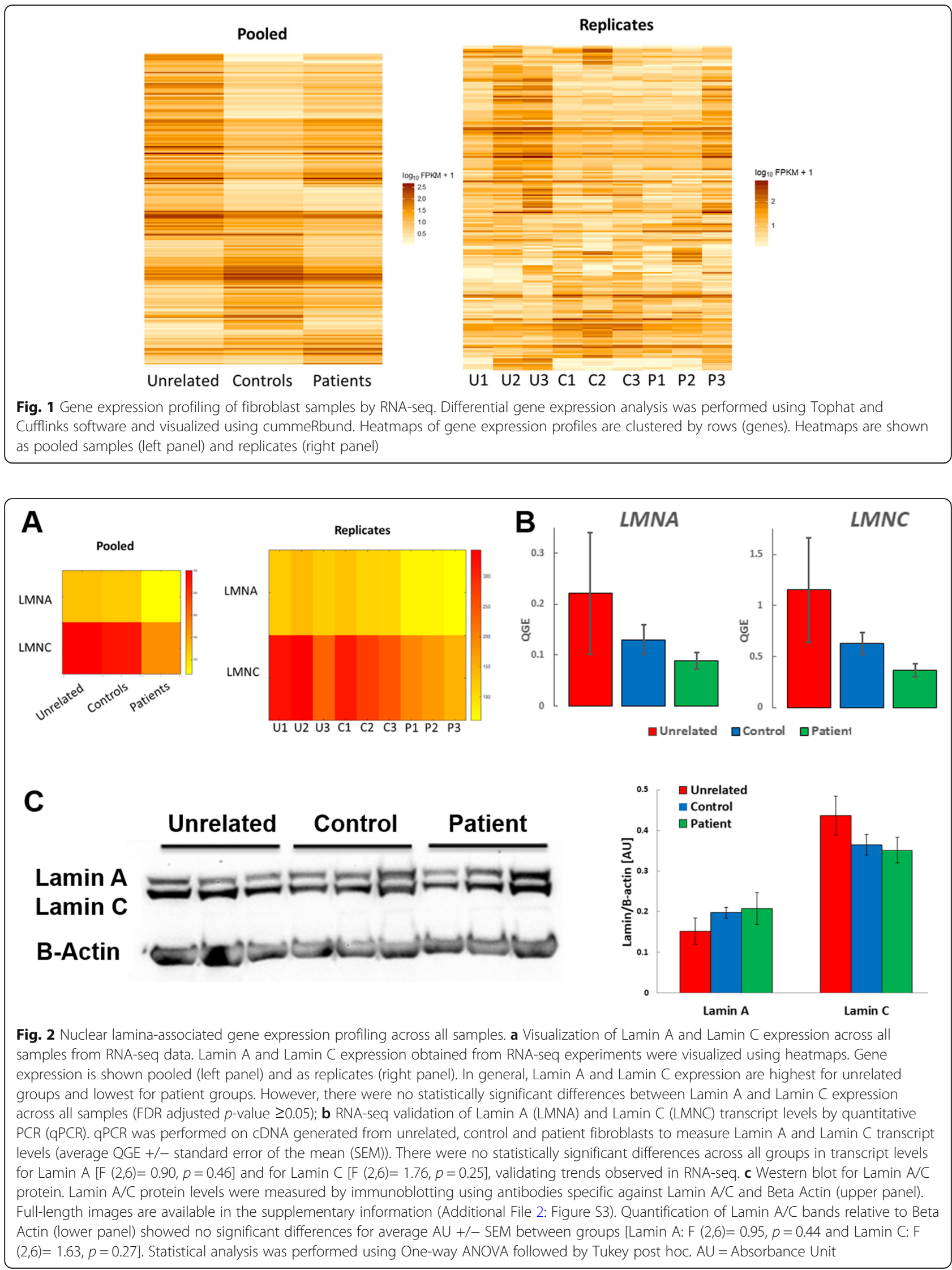
ERK/MAPK signaling pathway identified by DE and pathway analysis

Next, we turned our attention to other genes that were most significantly upregulated or downregulated between Patients, Controls, and Unrelated Controls. We found eight DE genes that were similarly expressed between the three groups (Fig. 4a, b). Among these eight DE genes were genes necessary for proper fibroblast physiological function such as Matrix Metallopeptidase 3 (MMP3) [45] and for epithelial-to-mesenchymal transition such as Keratin 18 (KRT18) [46]. In addition, we found one DE gene that was involved in the insulin-like growth factor (IGF) signaling pathway: IGFBP5. This gene was of particular interest due the known effects of Lamin $\mathrm{A} / \mathrm{C}$ on the IGF pathway in different forms of laminopathies [47]. Previous gene expression studies by microarray have reported IGFBP5 mRNA level to be downregulated in Lmna -/ - mouse embryonic fibroblasts, compared to Lmna +/+ mouse embryonic fibroblasts [48]. We also tested the DE gene expression in the RNA-seq data by performing qPCR on the IGFBP5 gene (Fig. 4c). The qPCR result showed similar trend as the RNA-seq data with Patient IGFBP5 gene expression decreased by greater than two-fold compared to Unrelated Controls. Finally, we used pathway analysis to demonstrate that these eight DE genes were connected in a gene network that included ERK/MAPK pathway genes (Fig. 5). This finding showed the connectivity of the DE genes in a signaling network and demonstrated the possibility of this pathway being affected in fibroblasts from $L M N A$-related cardiomyopathy patients.

\section{Discussion}

Compensatory role of IGFBP5 in maintaining ERK/MAPK pathway homeostasis in LMNA mutant fibroblasts

Here we report gene expression profiling using RNA-seq on fibroblasts from a family bearing a pathogenic $L M N A$ splice-site mutation. At present, the molecular mechanisms regulating tissue-specific manifestations of laminopathies are still unidentified. However, multiple studies have shown that $L M N A$ mutations cause nuclear envelope defects in mouse and human $L M N A$ mutant fibroblasts [49-51] and dysregulation of molecular signaling such as ERK/MAPK and Wnt Beta-Catenin pathways in mutant cardiac tissues $[9,10]$. In human cell lines, cultured cells from patients, and pluripotent stem cell disease models for $L M N A$-related diseases, upregulation of the ERK/ MAPK pathway also is documented $[52,53]$. Taken together, these studies suggested that laminopathies may arise from a combination of defects in the nuclear structure and the dysregulation of molecular signaling pathways in mutant cells.

Consistent with this, our gene expression profiling uncovered genes involved in signal transduction that are

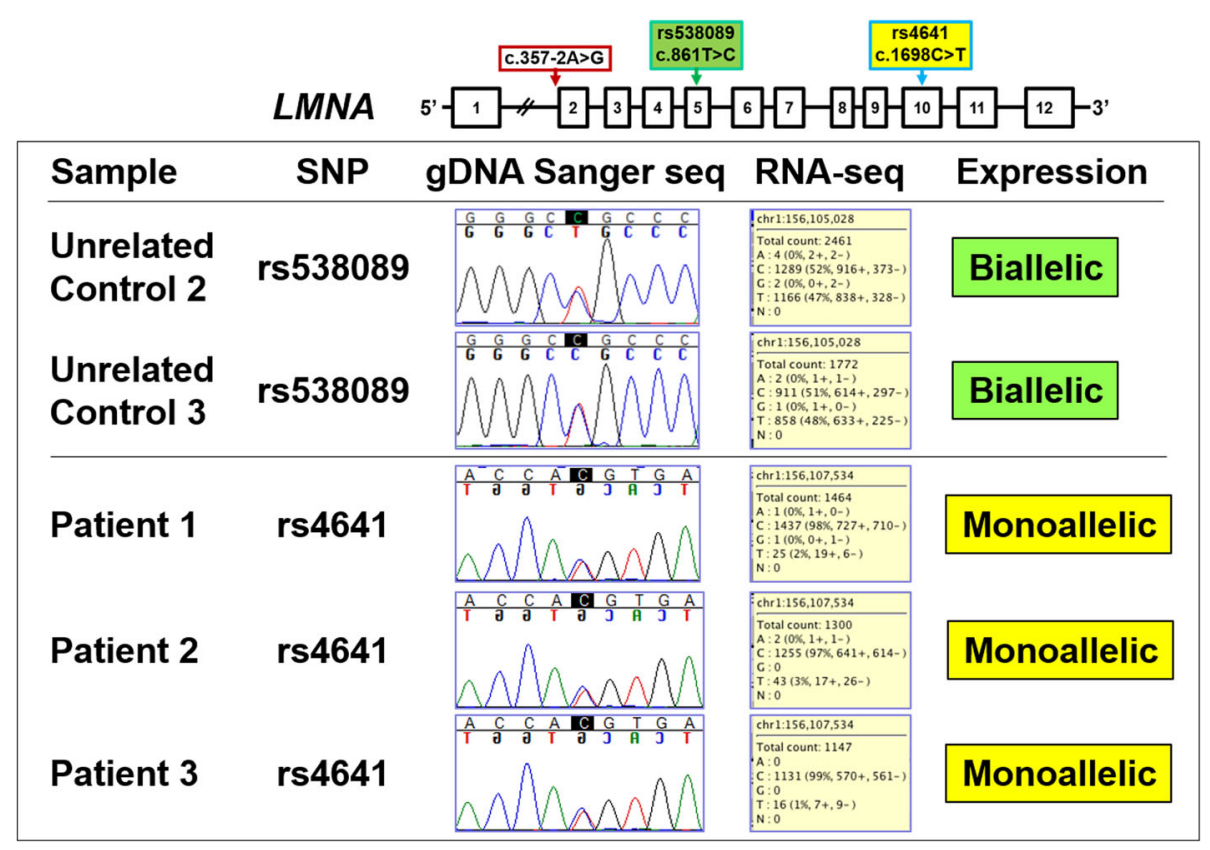

Fig. 3 LMNA allelic expression. Top panel depicts location of the LMNA splice-site mutation and two expressed single nucleotide polymorphisms (SNP), rs538089 in Exon 5 and rs4641 in Exon 10. Bottom table shows Sanger sequencing chromatograms from genomic DNA (gDNA) and distribution of allele read counts from RNA-seq. For two Unrelated Controls at rs538089, gDNA was heterozygous (C/T) with equal RNA-seq reads of C (51-52\%) and T (47-48\%) consistent with biallelic expression. For three Patients at rs4641, gDNA was heterozygous (C/T) with RNA-seq reads predominately of C (97-99\%) consistent with monoallelic expression 


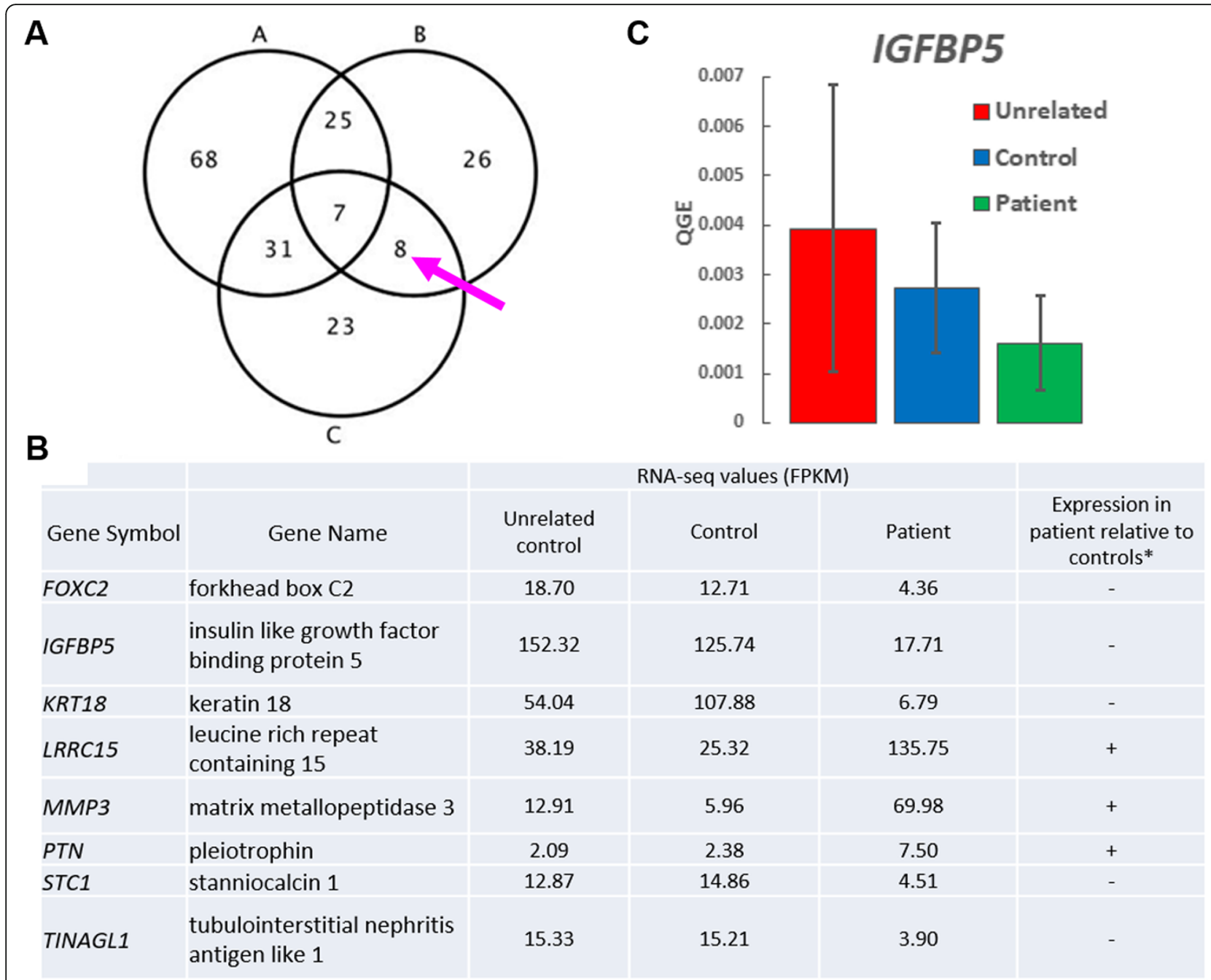

Fig. 4 Eight differentially expressed genes are potentially involved in LMNA-related cardiomyopathy. a Differentially expressed genes that passed the filtering criteria were input into Ingenuity Pathway Analysis (IPA). Of these significantly differentially expressed genes for each group, there were eight genes in the intersection (arrow) between $B$ and $C$, but not $A$, where $A=$ Unrelated vs. Controls, $B=$ Unrelated vs. Patients, $C=$ Controls vs. Patients; $\mathbf{b}$ Gene symbols, names, and RNA-seq values for eight genes found in the intersection between groups B and C, but not A; *Expression in patient: -: decreased, +: increased. c RNA-seq validation of Insulin Growth Factor binding protein 5 (IGFBP5) transcript levels by quantitative PCR (qPCR). qPCR was performed on CDNA generated from unrelated, control and patient fibroblasts to measure IGFBP5 transcript level. There was no statistically significant difference in IGFBP5 transcript levels (average QGE + /- SEM) between all groups $[F(2,6)=0.37, p=0.71]$. Statistical analysis was performed using One-way ANOVA followed by Tukey post hoc test

differentially expressed between LMNA mutant and normal human fibroblasts. Among eight significantly DE genes was the IGFBP5 gene that encodes for an IGF binding protein that stabilizes IGF cytokines to promote or inhibit its signaling cascade and subsequent IGF function in cell culture [54]. Aside from its cytokine binding function, IGFBP5 protein overexpression was shown to suppress cell growth in human melanoma, osteosarcoma, and breast cancer cell lines emphasizing its function in regulating cell proliferation [55-58]. Overexpression of IGFBP5 also was shown to enhance osteogenic differentiation in mesenchymal stem cells [59]. These observations resulted in increased phosphorylation of ERK1/2 and increased activity of the MAPK pathway, and predictably IGFBP5 knock down by shRNA reduced phosphorylation of ERK1/2 and subsequently downregulated the MAPK pathway [58-60]. Subsequently, our pathway analysis showed that the eight DE genes, including IGFBP5, were connected through the ERK/MAPK pathway. Our RNA-seq data showed a significant reduction in IGFBP5 gene expression in patient samples compared to control (7-fold reduction) and unrelated samples (9-fold reduction). This 


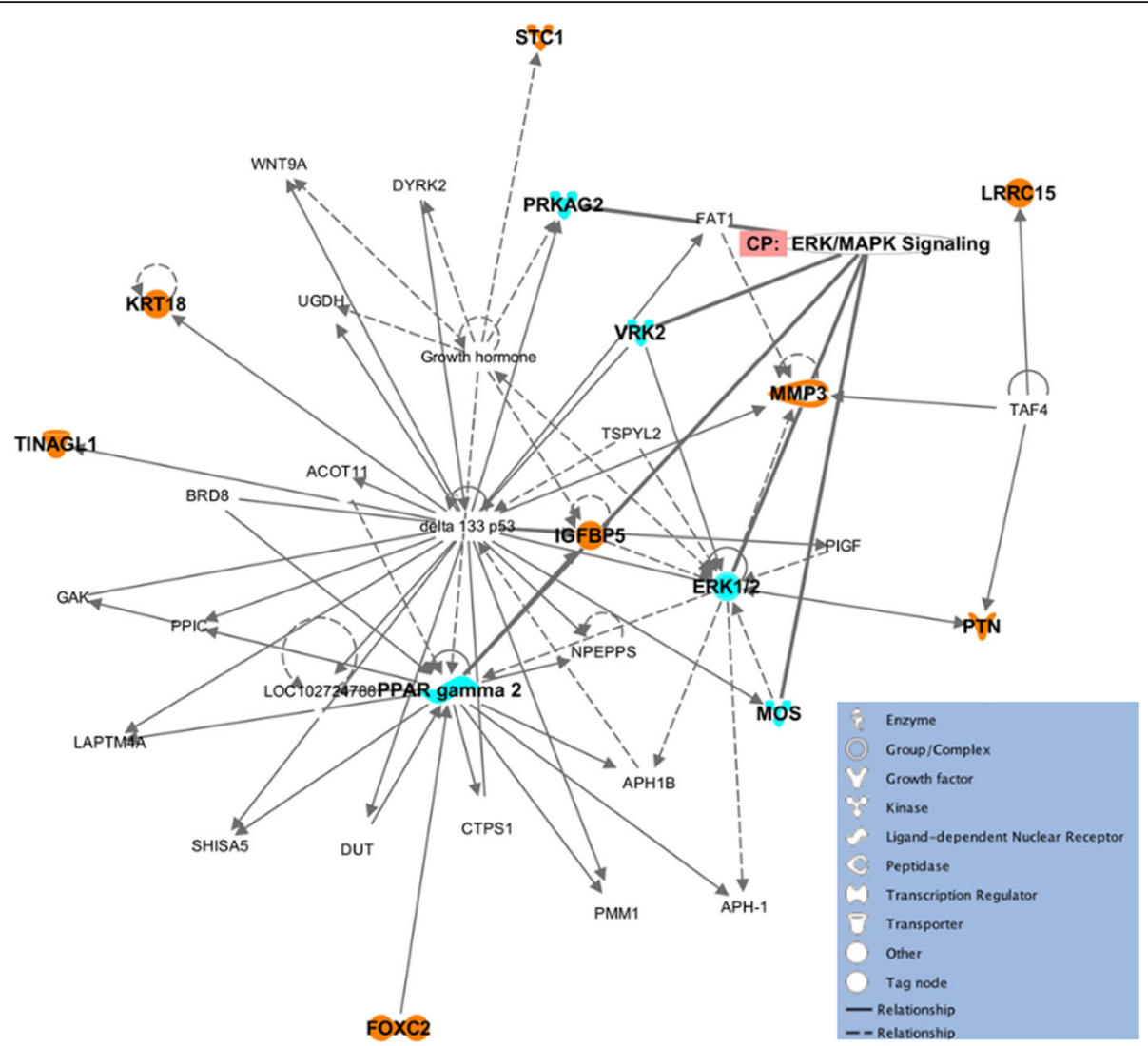

Fig. 5 Ingenuity Pathway Analysis (IPA) of network of eight DE genes. The eight genes that were found by the intersection shown in Fig. 3 were input into IPA to generate a network diagram with the most plausible connections to each other, and to additional genes in the IPA Knowledge Base. The eight genes of interest are highlighted in orange. A maximum of thirty-five genes are shown in the network for readability. The ERK MAPK pathways genes found in this network are highlighted in cyan

reduction may potentially impact the signaling pathways downstream to IGFBP5 binding. IGFBP5 protein translocates to the nucleus and interacts with Early growth response-1 transcription factor in human primary lung fibroblast to induce extracellular matrix production by activating the ERK/MAPK pathway, independent of the IGF pathway [61]. Since we did not detect any significant changes in the expression of canonical IGFBP5 binding partners, such as IGF1 and IGF2, or in IGF pathway activity, this suggests that the IGF pathway maintained its normal activity in patient fibroblasts. Taken together, these observations along with findings presented in published studies suggested that IGFBP5 exerts its effect through the ERK/MAPK pathway rather than the IGF pathway.

With these findings, we hypothesize that in unaffected tissues such as LMNA mutant fibroblasts, the significant reduction of IGFBP5 expression may contribute to maintaining homeostasis of the ERK/ MAPK signaling pathway and its downstream effects, masking the LMNA mutation phenotype. The postulation is supported by the observations of normal baseline ERK1/2 activity in patient fibroblasts [53]. In contrast, there is aberrant upregulation of ERK/ MAPK pathway in affected tissues such as LMNA mutant cardiomyocytes which leads to laminopathy phenotype [10,62]. Together, these mechanisms may provide an explanation for the absence of any significant phenotype in fibroblasts [63].

Another DE gene on the list, Forkhead Box C2 (FOXC2), whose overexpression induces hyperphosphorylation of ERK1/2 in cancer cells and is associated with aberrant cell proliferation [64], also has decreased mRNA expression in the affected individuals. FOXC2 mRNA reduction by shRNA silencing has been shown to downregulate ERK/ MAPK activity [64]. The downregulation of IGFBP5 and $F O X C 2$ gene expression may contribute to the compensatory mechanism that maintains the normal activity of ERK/ MAPK pathway and absence of observable phenotypes in fibroblasts. While the current study was performed on an unaffected tissue, we were able to gain insight on the possible signaling pathways and molecular mechanisms involved in the tissue specificity of laminopathies and $L M N A$ related cardiomyopathy. 


\section{Normal Lamin A/C protein levels by monoallelic expression and no compensation by B-type lamins in mutant fibroblasts}

Previously, we showed that there was monoallelic expression of LMNA gene in our patient fibroblasts, whereby only the wild type allele was expressed, and we predicted that the mutant allele expression was degraded by non-sense mediated mRNA decay [35]. In support of this, our RNA-seq results also showed $L M N A$ expression was predominately from the wild type allele (97-99\%) with no aberrantly spliced products from the mutant allele in patient fibroblasts.

We also found that there were no significant changes in $L M N A$ transcript levels, ratio of Lamin A to Lamin C transcripts, or expression of other NL-genes, LMNB1 and $L M N B 2$ between the Patient group and two control groups. These results are in line with our previous structural studies that found no significant difference in nuclear abnormalities and suggests that there were no compensatory mechanisms at the transcription level for the other proteins that construct the nuclear lamina [63].

Our results are in contrast to previous studies in patient fibroblasts that showed decreased Lamin A/C expression and altered ratio of Lamin A and Lamin C expression [65, 66]. Real-time PCR studies on fibroblasts from patients with a heterozygous $L M N A$ mutation at the splice site of intron 5 showed reduced $L M N A$ expression with the mutant $L M N A$ allele expressed at lower level compared to the normal allele [65]. In a different study, Lamin A protein expression was more diminished compared to Lamin C protein in fibroblasts from patients with Lamin-associated cardiomyopathies [66].

Numerous studies have reported that differential gene expression does not correlate directly with changes in protein expression [67-70]. Muchir et al. has previously reported that fibroblasts from EDMD, DCM and LGMD1B patients bearing heterozygous $L M N A$ mutations have similar Lamin $\mathrm{A} / \mathrm{C}$ protein levels compared to control fibroblasts [51]. Additional Lamin A/C protein studies in patient fibroblasts have also shown that heterozygous $L M N A$ mutations do not result in significantly observable phenotypes such as nuclear abnormalities or reduced protein level [52, 71-73].

Here, we performed validation studies for Lamin $\mathrm{A} / \mathrm{C}$ protein expression using Western Blot to resolve these discrepancies. We found that there was no significant differences in Lamin $\mathrm{A} / \mathrm{C}$ protein expression in mutant fibroblasts. This contrasts the decreased or absent levels of Lamin A/C protein detected previously in patient cardiac tissues [74, 75]. Thus, our results suggest that there is upregulated expression of wild type $L M N A$ allele in response to the degradation of the mutant allele or that expression of only one copy of the wild type allele is sufficient for normal levels of Lamin A/C protein to maintain normal physiological function in unaffected cell types. Other potential molecular mechanisms, such as epigenomic alterations specific to patient cardiac tissue $[34,76]$, tissue specific expression of Lamin proteins [17, 77], or differences in nuclear membrane proteome between tissues [78], may contribute to limit Lamin A/C haploinsufficiency to diseased cardiac tissues. Further studies comparing affected and unaffected tissues derived from the same patient or from patient-specific disease models may provide additional insight to the molecular mechanism of this mutation.

\section{Gene expression variabilities exist in samples within and between groups}

We obtained in total nine dermal fibroblast samples from affected, related unaffected, and unrelated individuals to perform RNA-seq. Though we age-matched and gender-matched the patients to controls to the best of our abilities, we found significant variability between samples within groups. While age is thought to be a factor that can influence gene expression [79], recent study on cultured fibroblasts in-vitro harvested from young, middle aged and older individuals revealed no significant difference in gene expression based on age groups [80]. The similarity between the published study and ours led us to conclude that short term in-vitro culture conditions are not sufficient to induce gene expression differences that are influenced by age.

Epigenomic modifications play a role in modulating gene expression [81-83]. We postulate that expression differences may arise from different degrees of epigenetic modifications accumulated or inherited by the individuals studied here throughout their lifetime. Our qualitative observations indicated that variabilities intrinsic to the samples must be taken into consideration when performing gene expression analysis. At present, we believe the expression differences we observed here are due to the small sample size available for our studies. These differences must be taken into account for future gene expression profiling studies by increasing our sample sizes and technical replicates per group.

\section{Conclusions}

Using deep RNA-seq and pathway analysis, we identified eight differentially expressed genes in fibroblasts from an affected family with a novel LMNA splice-site mutation and heart disease. Among these eight genes, we identified IGFBP5 as one of the candidate genes affected by $L M N A$ mutation and propose a possible molecular mechanism that explains the lack of significant molecular and structural phenotype in unaffected tissues. The identification of the ERK/MAPK pathway connecting the 
candidate genes together supports published studies that implicate this pathway in the development of LMNA-related cardiomyopathy. Our results for normal Lamin A/ $\mathrm{C}$ protein and LMNA gene expression from only the wild type allele in mutant fibroblasts also suggest that cardiac tissues are more sensitive to decreases in Lamin $\mathrm{A} / \mathrm{C}$ protein.

We are aware of the limitations of our studies as presented here. The variation of gene expression within and between sample groups introduced confounding factors to our analysis and our use of an unaffected tissue (fibroblasts) instead of affected tissue (cardiomyocytes) result in a partial explanation of the molecular mechanisms of this particular LMNA splice-site mutation. Thus, our results indicate the necessity to develop a model system to study this disease in vitro. To that end, we will generate patient-specific induced pluripotent stem cells lines that will be differentiated to cardiomyocytes for molecular studies to confirm the proposed tissue-specific mechanism of disease.

\section{Supplementary information}

Supplementary information accompanies this paper at https://doi.org/10. 1186/s12881-020-01088-w.

Additional file 1: Table S1. Sequencing statistics. Table S2. qPCR primer sequences. Table S3. RNA-seq expression values for LMNA, LMNC, and IGFBP5.

Additional file 2: Figure S1. IGV screenshots showing expression of LMNA transcripts at exons 1, 2 and 3. Figure S2. Lamin B1 and Lamin B2 heatmap and qPCR validation. Figure S3. Original Lamin A/C Western Blot.

\section{Abbreviations}

NL: Nuclear lamina; DCM: Dilated cardiomyopathy; EDMD: Emery-Dreyfus Muscular Dystrophy; LGMD1B: Limb Girdle Muscular Dystrophy type 1B; RNAseq: RNA sequencing; P: Patient; C: Control; U: Unrelated Control; gDNA: Genomic DNA; DE: Differential expression; FPKM: Fragments Per Kilobase of transcript per Million mapped reads; FDR: False discovery rate; IGV: Integrative Genomics Viewer; IPA: Ingenuity Pathway Analysis; qPCR: Quantitative PCR; QGE: Quantitative gene expression; IGF: Insulin-like growth factor; SEM: Standard error of the mean

\section{Acknowledgments}

We are grateful to our study family.

\section{Authors' contributions}

TMN, HPW, AG and MVZ conceived of the project and designed experiments. MVZ performed tissue culture and gDNA/RNA extractions. TMN performed bioinformatics data analysis. HPW performed QPCR and Western blot experiments. TMN, HP and MVZ analyzed data and wrote the manuscript. MVZ and AG provided funding and supervised the project. All authors discussed results, reviewed and edited the manuscript. The authors read and approved the final manuscript.

\section{Funding}

This work was supported by grant 1R01HL129008 from the NIH National Heart, Lung, and Blood Institute (MVZ and AG). The funding source did not play a role in the design of this study, data collection, analysis and interpretation, and writing the manuscript.

\section{Availability of data and materials}

The RNA-seq dataset supporting the conclusions of this article is available from the NCBI Gene Expression Omnibus (GEO), Accession: GSE125990, and accessible via the following link:

[https://www.ncbi.nlm.nih.gov/geo/query/acc.cgi?acc=GSE125990]. In addition, the dataset for Human reference genome (GRCh37/hg19) is available from the National Center for Biotechnology Information via the

following link: [https://www.ncbi.nlm.nih.gov/assembly/GCF_000001405.13/].

\section{Ethics approval and consent to participate}

The study was approved by the University of California Institutional Review Board (Protocol 2011-8030). All affected and unaffected study family members gave their informed written consent before they participated in the study. All procedures were conducted in accordance with the ethical standards of the institution and with the Declaration of Helsinki,

\section{Consent for publication}

Not applicable since no identifiable information is included in this publication.

\section{Competing interests}

The authors declare that they have no competing interests.

\section{Author details}

${ }^{1}$ UCI Cardiogenomics Program, Department of Pediatrics, Division of Genetics \& Genomics and Department of Biological Chemistry, University of California, Irvine, School of Medicine, 2042 Hewitt Hall, Irvine, CA 92697-3940, USA. ${ }^{2}$ Department of Epidemiology, University of California, Irvine, School of Medicine, 3062 Anteater Instruction and Research Building, Irvine, CA 92697-7550, USA. ${ }^{3}$ Department of Biomedical Engineering and The Edwards Lifesciences Center for Advanced Cardiovascular Technology, University of

California, Irvine, Irvine, California, USA.

Received: 31 March 2020 Accepted: 6 July 2020

Published online: 22 July 2020

References

1. Burke $B$, Stewart $\mathrm{CL}$. The nuclear lamins: flexibility in function. Nat Rev Mol Cell Biol. 2013;14(1):13-24.

2. Dechat T, Adam SA, Taimen P, Shimi T, Goldman RD. Nuclear lamins. Cold Spring Harb Perspect Biol. 2010;2(11):a000547.

3. Prokocimer M, Davidovich M, Nissim-Rafinia M, Wiesel-Motiuk N, Bar DZ, Barkan R, et al. Nuclear lamins: key regulators of nuclear structure and activities. J Cell Mol Med. 2009;13(6):1059-85.

4. Wang Y, Ostlund C, Choi JC, Swayne TC, Gundersen GG, Worman HJ. Blocking farnesylation of the prelamin a variant in Hutchinson-Gilford progeria syndrome alters the distribution of A-type lamins. Nucleus. 2012; 3(5):452-62

5. Sullivan T, Escalante-Alcalde D, Bhatt H, Anver M, Bhat N, Nagashima K, et al. Loss of A-type Lamin expression compromises nuclear envelope integrity leading to muscular dystrophy. J Cell Biol. 1999;147(5):913-20.

6. Guelen L, Pagie L, Brasset E, Meuleman W, Faza MB, Talhout W, et al. Domain organization of human chromosomes revealed by mapping of nuclear lamina interactions. Nature. 2008:453(7197):948-51.

7. Ho CY, Lammerding J. Lamins at a glance. J Cell Sci. 2012;125(Pt 9):2087-93.

8. Johnson BR, Nitta RT, Frock RL, Mounkes $L$, Barbie DA, Stewart $C L$, et al. Atype lamins regulate retinoblastoma protein function by promoting subnuclear localization and preventing proteasomal degradation. Proc Natl Acad Sci U S A. 2004;101(26):9677-82.

9. Le Dour C, Macquart C, Sera F, Homma S, Bonne G, Morrow JP, et al. Decreased WNT/beta-catenin signalling contributes to the pathogenesis of dilated cardiomyopathy caused by mutations in the Lamin A/C gene. Hum Mol Genet. 2017;26(2):333-43.

10. Muchir A, Pavlidis P, Decostre V, Herron AJ, Arimura T, Bonne G, et al. Activation of MAPK pathways links LMNA mutations to cardiomyopathy in Emery-Dreifuss muscular dystrophy. J Clin Invest. 2007;117(5):1282-93.

11. Muchir A, Wu W, Choi JC, Iwata S, Morrow J, Homma S, et al. Abnormal p38alpha mitogen-activated protein kinase signaling in dilated cardiomyopathy caused by Lamin A/C gene mutation. Hum Mol Genet. 2012;21(19):4325-33. 
12. Rober RA, Weber K, Osborn M. Differential timing of nuclear Lamin A/C expression in the various organs of the mouse embryo and the young animal: a developmental study. Development. 1989;105(2):365-78.

13. Constantinescu D, Gray HL, Sammak PJ, Schatten GP, Csoka AB. Lamin A/C expression is a marker of mouse and human embryonic stem cell differentiation. Stem Cells. 2006;24(1):177-85.

14. Vergnes L, Peterfy M, Bergo MO, Young SG, Reue K. Lamin B1 is required for mouse development and nuclear integrity. Proc Natl Acad Sci U S A. 2004; 101(28):10428-33.

15. Coffinier C, Jung HJ, Nobumori C, Chang S, Tu Y, Barnes RH 2nd, et al. Deficiencies in Lamin B1 and Lamin B2 cause neurodevelopmental defects and distinct nuclear shape abnormalities in neurons. Mol Biol Cell. 2011; 22(23):4683-93.

16. Stewart C, Burke B. Teratocarcinoma stem cells and early mouse embryos contain only a single major Lamin polypeptide closely resembling Lamin B. Cell. 1987;51(3):383-92.

17. Talamas JA, Capelson M. Nuclear envelope and genome interactions in cell fate. Front Genet. 2015;6:95

18. Fatkin D, MacRae C, Sasaki T, Wolff MR, Porcu M, Frenneaux M, et al. Missense mutations in the rod domain of the Lamin A/C gene as causes of dilated cardiomyopathy and conduction-system disease. N Engl J Med. 1999;341(23):1715-24.

19. Becane HM, Bonne G, Varnous S, Muchir A, Ortega V, Hammouda EH, et al. High incidence of sudden death with conduction system and myocardial disease due to lamins a and C gene mutation. Pacing Clin Electrophysiol. 2000;23(11 Pt 1):1661-6.

20. Pan H, Richards AA, Zhu X, Joglar JA, Yin HL, Garg V. A novel mutation in Lamin $A / C$ is associated with isolated early-onset atrial fibrillation and progressive atrioventricular block followed by cardiomyopathy and sudden cardiac death. Heart Rhythm. 2009;6(5):707-10.

21. Bonne G, Mercuri E, Muchir A, Urtizberea A, Becane HM, Recan D, et al. Clinical and molecular genetic spectrum of autosomal dominant EmeryDreifuss muscular dystrophy due to mutations of the Lamin A/C gene. Ann Neurol. 2000:48(2):170-80.

22. Frock RL, Kudlow BA, Evans AM, Jameson SA, Hauschka SD, Kennedy BK. Lamin A/C and emerin are critical for skeletal muscle satellite cell differentiation. Genes Dev. 2006;20(4):486-500

23. Favreau C, Delbarre E, Courvalin JC, Buendia B. Differentiation of C2C12 myoblasts expressing Lamin a mutated at a site responsible for Emery-Dreifuss muscular dystrophy is improved by inhibition of the MEK-ERK pathway and stimulation of the PI3-kinase pathway. Exp Cell Res. 2008;314(6):1392-405.

24. Muchir A, van Engelen BG, Lammens M, Mislow JM, McNally E, Schwartz K, et al. Nuclear envelope alterations in fibroblasts from LGMD1B patients carrying nonsense Y259X heterozygous or homozygous mutation in Lamin A/C gene. Exp Cell Res. 2003;291(2):352-62.

25. De Sandre-Giovannoli A, Bernard R, Cau P, Navarro C, Amiel J, Boccaccio I, et al. Lamin a truncation in Hutchinson-Gilford progeria. Science. 2003; 300(5628):2055 Epub 2003/04/19.

26. Eriksson M, Brown WT, Gordon LB, Glynn MW, Singer J, Scott $L$, et al. Recurrent de novo point mutations in Lamin a cause Hutchinson-Gilford progeria syndrome. Nature. 2003;423(6937):293-8.

27. Herman DS, Lam L, Taylor MR, Wang L, Teekakirikul P, Christodoulou D, et al, Truncations of titin causing dilated cardiomyopathy. N Engl J Med. 2012; 366(7):619-28

28. Mestroni L, Brun F, Spezzacatene A, Sinagra G, Taylor MR. Genetic causes of dilated cardiomyopathy. Prog Pediatr Cardiol. 2014;37(1-2):13-8.

29. Taylor MR, Fain PR, Sinagra G, Robinson ML, Robertson AD, Carniel E, et al. Natural history of dilated cardiomyopathy due to Lamin A/C gene mutations. J Am Coll Cardiol. 2003:41(5):771-80.

30. Dellefave L, McNally EM. The genetics of dilated cardiomyopathy. Curr Opin Cardiol. 2010;25(3):198-204

31. Hershberger RE, Morales A. LMNA-Related Dilated Cardiomyopathy. In: Adam MP, Ardinger HH, Pagon RA, Wallace SE, Bean LJH, Stephens K, et al., editors. GeneReviews ${ }^{\circledast}$. Seattle (WA): University of Washington, Seattle; 1993.

32. Brayson D, Shanahan CM. Current insights into LMNA cardiomyopathies: existing models and missing LINCs. Nucleus. 2017;8(1):17-33.

33. Jaalouk DE, Lammerding J. Mechanotransduction gone awry. Nat Rev Mol Cell Biol. 2009;10(1):63-73.

34. Perovanovic J, Dell'Orso S, Gnochi VF, Jaiswal JK, Sartorelli V, Vigouroux C, et al. Laminopathies disrupt epigenomic developmental programs and cell fate. Sci Transl Med. 2016;8(335):335ra58.
35. Zaragoza MV, Fung L, Jensen E, Oh F, Cung K, McCarthy LA, et al. Exome sequencing identifies a novel LMNA splice-site mutation and multigenic Heterozygosity of potential modifiers in a family with sick sinus syndrome, dilated cardiomyopathy, and sudden cardiac death. PLoS One. 2016;11(5): e0155421.

36. Andrews S. FastQC: a quality control tool for high throughput sequence data. 2010. Available online: www.bioinformatics.babraham.ac.uk/projects/fastqc.

37. Kim D, Pertea G, Trapnell C, Pimentel H, Kelley R, Salzberg SL. TopHat2: accurate alignment of transcriptomes in the presence of insertions, deletions and gene fusions. Genome Biol. 2013;14(4):R36.

38. Trapnell C, Roberts A, Goff L, Pertea G, Kim D, Kelley DR, et al. Differential gene and transcript expression analysis of RNA-seq experiments with TopHat and cufflinks. Nat Protoc. 2012:7(3):562-78.

39. Trapnell C, Hendrickson DG, Sauvageau M, Goff L, Rinn JL, Pachter L. Differential analysis of gene regulation at transcript resolution with RNA-seq. Nat Biotechnol. 2013;31(1):46-53.

40. Goff L, Trapnell C, Kelley D. cummeRbund: Analysis, exploration, manipulation, and visualization of Cufflinks high-throughput sequencing data. 2019. R package version 2.28.0. Available online: bioconductor.riken.jp/ packages/3.10/bioc/html/cummeRbund.html.

41. Robinson JT, Thorvaldsdóttir H, Winckler W, Guttman M, Lander ES, Getz G, et al. Integrative genomics viewer. Nat Biotechnol. 2011;29(1):24-6.

42. Livak KJ, Schmittgen TD. Analysis of relative gene expression data using real-time quantitative PCR and the 2(-Delta Delta C(T)) method. Methods. 2001;25(4):402-8.

43. Schmittgen TD, Livak KJ. Analyzing real-time PCR data by the comparative C(T) method. Nat Protoc. 2008:3(6):1101-8.

44. Schneider CA, Rasband WS, Eliceiri KW. NIH image to ImageJ: 25 years of image analysis. Nat Methods. 2012;9(7):671-5.

45. Lindner D, Zietsch C, Becher PM, Schulze K, Schultheiss HP, Tschope C, et al. Differential expression of matrix metalloproteases in human fibroblasts with different origins. Biochem Res Int. 2012;2012:875742.

46. Jung $H$, Kim B, Moon Bl, Oh ES. Cytokeratin 18 is necessary for initiation of TGF-beta1-induced epithelial-mesenchymal transition in breast epithelial cells. Mol Cell Biochem. 2016;423(1-2):21-8.

47. Marino G, Ugalde AP, Fernandez AF, Osorio FG, Fueyo A, Freije JM, et al. Insulin-like growth factor 1 treatment extends longevity in a mouse model of human premature aging by restoring somatotroph axis function. Proc Natl Acad Sci U S A. 2010;107(37):16268-73.

48. Singh M, Hunt CR, Pandita RK, Kumar R, Yang CR, Horikoshi N, et al. Lamin $A / C$ depletion enhances DNA damage-induced stalled replication fork arrest. Mol Cell Biol. 2013;33(6):1210-22.

49. Raharjo WH, Enarson P, Sullivan T, Stewart CL, Burke B. Nuclear envelope defects associated with LMNA mutations cause dilated cardiomyopathy and Emery-Dreifuss muscular dystrophy. J Cell Sci. 2001;114(Pt 24):4447-57.

50. Ho JC, Zhou T, Lai WH, Huang Y, Chan YC, Li X, et al. Generation of induced pluripotent stem cell lines from 3 distinct laminopathies bearing heterogeneous mutations in Lamin A/C. Aging. 2011;3(4):380-90.

51. Muchir A, Medioni J, Laluc M, Massart C, Arimura T, van der Kooi AJ, et al. Nuclear envelope alterations in fibroblasts from patients with muscular dystrophy, cardiomyopathy, and partial lipodystrophy carrying Lamin a/C gene mutations. Muscle Nerve. 2004;30(4):444-50.

52. Emerson $L$, Holt MR, Wheeler MA, Wehnert M, Parsons M, Ellis JA. Defects in cell spreading and ERK1/2 activation in fibroblasts with Lamin A/C mutations. Biochim Biophys Acta. 2009;1792(8):810-21.

53. Siu CW, Lee YK, Ho JC, Lai WH, Chan YC, Ng KM, et al. Modeling of Lamin $\mathrm{A} / \mathrm{C}$ mutation premature cardiac aging using patient-specific induced pluripotent stem cells. Aging. 2012;4(11):803-22.

54. Denduluri SK, Idowu O, Wang Z, Liao Z, Yan Z, Mohammed MK, et al. Insulin-like growth factor (IGF) signaling in tumorigenesis and the development of cancer drug resistance. Genes Dis. 2015;2(1):13-25.

55. Schedlich $\amalg$, Young TF, Firth SM, Baxter RC. Insulin-like growth factor-binding protein (IGFBP)-3 and IGFBP-5 share a common nuclear transport pathway in T47D human breast carcinoma cells. J Biol Chem. 1998:273(29):18347-52.

56. Schedlich $L$, Le Page SL, Firth SM, Briggs LJ, Jans DA, Baxter RC. Nuclear import of insulin-like growth factor-binding protein-3 and -5 is mediated by the importin beta subunit. J Biol Chem. 2000;275(31):23462-70.

57. Suh YA, Kim JH, Sung MA, Boo HJ, Yun HJ, Lee SH, et al. A novel antitumor activity of deguelin targeting the insulin-like growth factor (IGF) receptor pathway via up-regulation of IGF-binding protein-3 expression in breast cancer. Cancer Lett. 2013;332(1):102-9. 
58. Wang J, Ding N, Li Y, Cheng H, Wang D, Yang Q, et al. Insulin-like growth factor binding protein 5 (IGFBP5) functions as a tumor suppressor in human melanoma cells. Oncotarget. 2015;6(24):20636-49.

59. Wang $Y$, Jia Z, Diao S, Lin X, Lian X, Wang L, et al. IGFBP5 enhances osteogenic differentiation potential of periodontal ligament stem cells and Wharton's jelly umbilical cord stem cells, via the JNK and MEK/Erk signalling pathways. Cell Prolif. 2016;49(5):618-27.

60. Lee DH, Kim JE, Kang YJ. Insulin like growth factor binding Protein-5 regulates excessive vascular smooth muscle cell proliferation in spontaneously hypertensive rats via ERK 1/2 phosphorylation. Korean J Physiol Pharmacol. 2013;17(2):157-62.

61. Yasuoka H, Hsu E, Ruiz XD, Steinman RA, Choi AM, Feghali-Bostwick CA. The fibrotic phenotype induced by IGFBP-5 is regulated by MAPK activation and egr-1-dependent and -independent mechanisms. Am J Pathol. 2009;175(2): 605-15.

62. Muchir A, Reilly SA, Wu W, Iwata S, Homma S, Bonne G, et al. Treatment with selumetinib preserves cardiac function and improves survival in cardiomyopathy caused by mutation in the Lamin A/C gene. CardiovasC Res. 2012:93(2):311-9.

63. Core JQ, Mehrabi M, Robinson ZR, Ochs AR, McCarthy LA, Zaragoza MV, et al. Age of heart disease presentation and dysmorphic nuclei in patients with LMNA mutations. PLoS One. 2017;12(11):e0188256.

64. Cui YM, Jiang D, Zhang SH, Wu P, Ye YP, Chen CM, et al. FOXC2 promotes colorectal cancer proliferation through inhibition of FOXO3a and activation of MAPK and AKT signaling pathways. Cancer Lett. 2014;353(1):87-94.

65. Carboni N, Floris M, Mateddu A, Porcu M, Marrosu G, Solla E, et al. Aberrant splicing in the LMNA gene caused by a novel mutation on the polypyrimidine tract of intron 5. Muscle Nerve. 2011;43(5):688-93.

66. Al-Saaidi R, Rasmussen TB, Palmfeldt J, Nissen PH, Beqqali A, Hansen J, et al. The LMNA mutation p.Arg321Ter associated with dilated cardiomyopathy leads to reduced expression and a skewed ratio of Lamin a and Lamin C proteins. Exp Cell Res. 2013;319(19):3010-9.

67. de Sousa AR, Penalva LO, Marcotte EM, Vogel C. Global signatures of protein and mRNA expression levels. Mol BioSyst. 2009;5(12):1512-26 Epub 2009/12/22

68. Maier T, Guell M, Serrano L. Correlation of mRNA and protein in complex biological samples. FEBS Lett. 2009;583(24):3966-73.

69. Vogel C, Marcotte EM. Insights into the regulation of protein abundance from proteomic and transcriptomic analyses. Nat Rev Genet. 2012;13(4):22732 Epub 2012/03/14.

70. Koussounadis A, Langdon SP, Um $\Vdash$, Harrison DJ, Smith VA. Relationship between differentially expressed mRNA and mRNA-protein correlations in a xenograft model system. Sci Rep. 2015;5:10775.

71. Vigouroux C, Auclair M, Dubosclard E, Pouchelet M, Capeau J, Courvalin JC, et al. Nuclear envelope disorganization in fibroblasts from lipodystrophic patients with heterozygous R482Q/W mutations in the Lamin A/C gene. J Cell Sci. 2001;114(Pt 24):4459-68.

72. Caux F, Dubosclard E, Lascols O, Buendia B, Chazouilleres O, Cohen A, et al. A new clinical condition linked to a novel mutation in lamins a and $C$ with generalized lipoatrophy, insulin-resistant diabetes, disseminated leukomelanodermic papules, liver steatosis, and cardiomyopathy. J Clin Endocrinol Metab. 2003;88(3):1006-13.

73. Favreau C, Dubosclard E, Ostlund C, Vigouroux C, Capeau J, Wehnert M, et al. Expression of Lamin a mutated in the carboxyl-terminal tail generates an aberrant nuclear phenotype similar to that observed in cells from patients with Dunnigan-type partial lipodystrophy and Emery-Dreifuss muscular dystrophy. Exp Cell Res. 2003;282(1):14-23.

74. Arbustini E, Pilotto A, Repetto A, Grasso M, Negri A, Diegoli M, et al. Autosomal dominant dilated cardiomyopathy with atrioventricular block: a Lamin A/C defect-related disease. J Am Coll Cardiol. 2002;39(6):981-90.

75. Narula N, Favalli V, Tarantino P, Grasso M, Pilotto A, Bellazzi R, et al. Quantitative expression of the mutated Lamin A/C gene in patients with cardiolaminopathy. J Am Coll Cardiol. 2012;60(19):1916-20.

76. Poleshko A, Shah PP, Gupta M, Babu A, Morley MP, Manderfield LJ, et al. Genome-nuclear Lamina interactions regulate cardiac stem cell lineage restriction. Cell. 2017;171(3):573-87 e14.

77. Dittmer TA, Misteli T. The Lamin protein family. Genome Biol. 2011;12(5):222.

78. Korfali N, Wilkie GS, Swanson SK, Srsen V, de Las HJ, Batrakou DG, et al. The nuclear envelope proteome differs notably between tissues. Nucleus. 2012; 3(6):552-64.
79. Jiang Y, Mishima H, Sakai S, Liu YK, Ohyabu Y, Uemura T. Gene expression analysis of major lineage-defining factors in human bone marrow cells: effect of aging, gender, and age-related disorders. J Orthop Res. 2008;26(7): 910-7.

80. Kaisers W, Boukamp P, Stark HJ, Schwender H, Tigges J, Krutmann J, et al. Age, gender and UV-exposition related effects on gene expression in in vivo aged short term cultivated human dermal fibroblasts. PLoS One 2017;12(5):e0175657.

81. Jaenisch R, Bird A. Epigenetic regulation of gene expression: how the genome integrates intrinsic and environmental signals. Nat Genet. 2003; 33(Suppl):245-54.

82. Grewal SI, Moazed D. Heterochromatin and epigenetic control of gene expression. Science. 2003;301(5634):798-802.

83. Fraga MF, Ballestar E, Paz MF, Ropero S, Setien F, Ballestar ML, et al. Epigenetic differences arise during the lifetime of monozygotic twins. Proc Natl Acad Sci U S A. 2005;102(30):10604-9.

\section{Publisher's Note}

Springer Nature remains neutral with regard to jurisdictional claims in published maps and institutional affiliations.
Ready to submit your research? Choose BMC and benefit from:

- fast, convenient online submission

- thorough peer review by experienced researchers in your field

- rapid publication on acceptance

- support for research data, including large and complex data types

- gold Open Access which fosters wider collaboration and increased citations

- maximum visibility for your research: over $100 \mathrm{M}$ website views per year

At BMC, research is always in progress.

Learn more biomedcentral.com/submissions 